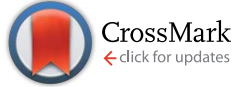

Cite this: RSC Adv., 2017, 7, 9057
Received 15th December 2016 Accepted 21st January 2017

DOI: $10.1039 / c 6 r a 28237 g$

rsc.li/rsc-advances

\section{Pharmacokinetics of rosmarinic acid in rats by LC- MS/MS: absolute bioavailability and dose proportionality}

\author{
Jingxian Wang, $\dagger^{\mathrm{ab}}$ Guoyuan Li, $\uparrow^{\mathrm{ab}}$ Tianqi Rui, ${ }^{\mathrm{ab}}$ An Kang, ${ }^{\mathrm{ab}}$ Guochun Li, ${ }^{\mathrm{C}}$ \\ Tingming $\mathrm{Fu}^{\mathrm{ab}}$ Junsong $\mathrm{Li}^{\text {*ab }}{ }^{\mathrm{ab}}$ Liuqing $\mathrm{Di}^{\mathrm{ab}}$ and Baochang $\mathrm{Cai}^{\mathrm{a}}$
}

Rosmarinic acid (RA), one of the main bioactive compounds of Rosmarinus officinalis L., exhibits diverse pharmacological effects. However, its oral absolute bioavailability and dose proportionality in vivo have not been comprehensively studied. In the present study, a validated LC-MS/MS method was developed for the determination of RA in rat plasma. Pharmacokinetic parameters were obtained following oral and intravenous dosing using DAS 3.0 software. Absolute bioavailability in rats was determined by comparing pharmacokinetic data after administration of single oral $(12.5,25$ and $50 \mathrm{mg}$ $\left.\mathrm{kg}^{-1}\right)$ and intravenous $\left(0.625 \mathrm{mg} \mathrm{kg}^{-1}\right)$ doses of RA. The dose proportionality of AUC and $C_{\max }$ were analyzed using a power model. After single-dose oral administration of RA, $C_{\max }$ values for groups with 12.5, 25 and $50 \mathrm{mg} \mathrm{kg}^{-1}$ doses ranged from 215.29 to $790.96 \mathrm{ng} \mathrm{mL}^{-1}$, with $\mathrm{AUC}_{0-t}$ values from 41789.84 to $96070.00 \mathrm{~min} \mathrm{ng} \mathrm{mL}^{-1}$, while $T_{\max }$ and $t_{1 / 2}$ values ranged from 8.33 to 18.33 and from 332.34 to $295.32 \mathrm{~min}$, respectively. The power model showed RA lacked dose proportionality over the dose range from $12.5-50 \mathrm{mg} \mathrm{kg}^{-1}$. Oral absolute bioavailability was calculated to range from $0.91 \%$ to $1.69 \%$. All the results demonstrated that the pharmacokinetic properties of RA in rats after oral administration were characterized as rapid absorption, middle-speed elimination and poor absolute bioavailability. Systemic exposure exhibited lack of dose proportionality over the dose range from 12.5 to $50 \mathrm{mg} \mathrm{kg}^{-1}$. These presented data could provide useful information for the rational clinical application and optimal dosage form design of RA.

\section{Introduction}

Rosemary, Rosmarinus officinalis L. (Labiatae), is used in folk medicine worldwide for initial health care among a variety of plants. It is an evergreen perennial shrub native to Asia Minor and southern Europe. Today it has been cultivated in many parts of the world. ${ }^{\mathbf{1} 2}$ The powerful antioxidant activity of its constituents supports protection against damage induced by free radicals. ${ }^{3,4}$ Furthermore, it has been demonstrated that Rosmarinus officinalis produces an antinociceptive effect in experimental models of pain like acetic acid and formalin, but also in the pain-induced functional impairment model in rats. ${ }^{5}$ According to phytochemical reports, rosmarinic acid (RA) (Fig. 1) is the main effective, water-soluble polyphenolic

${ }^{a}$ College of Pharmacy, Nanjing University of Chinese Medicine, 138 Xianlin Avenue, Nanjing 210023, China. E-mail: lijunsong1964@163.com; Fax: +86-25-85811517; Tel: +86-25-85811517

bjiangsu Provincial TCM Engineering Technology Research Center of High Efficient Drug Delivery System (DDS), Nanjing 210023, China

${ }^{c}$ The Center of Statistical Research and Consultation of TCM, Nanjing University of Chinese Medicine, Nanjing 210023, China

$\uparrow$ Contributed equally. acid from Rosemary, which was found to have various curative activities, such as anti-inflammatory, ${ }^{6,7}$ antioxidant, ${ }^{8}$ anticancer, $^{\mathbf{9}, 10}$ antimicrobial ${ }^{1 \mathbf{1 1}}$ and anti-diabetes ${ }^{\mathbf{1 2}}$ properties. Recent studies also showed that it could improve cognitive performance. ${ }^{13}$ For safety and efficacy reasons, it is important to understand the real-time effective levels of phytochemicals in the systemic circulation and the time course concentrations following oral administration. Besides, research on bioavailability plays a very important role in the development of a drug and its clinical use.

To date, several pharmacokinetic studies for RA have been reported in human or animals. Most of these studies on pharmacokinetics of RA were accomplished by oral administration of a single herb, ${ }^{\mathbf{1 4 , 1 5}}$ compound prescription extract ${ }^{\mathbf{1 6 , 1 7}}$ or mixture containing RA. ${ }^{\mathbf{1 8}, 19}$ On the other hand, the pharmacokinetics of RA after pure RA treatment only has been roughly or partially carried out. ${ }^{\mathbf{2 0 , 2 1}}$ These pharmacokinetics studies have enabled us to understand the absorption characteristics of RA in vivo. But a systemic pharmacokinetic study of RA, especially with gradient dosages, after single RA treatment still remains to be done.

Phenolic acids were usually reported with low oral bioavailability. ${ }^{22,23}$ In Caco-2 cells' model, RA transport was mainly via 

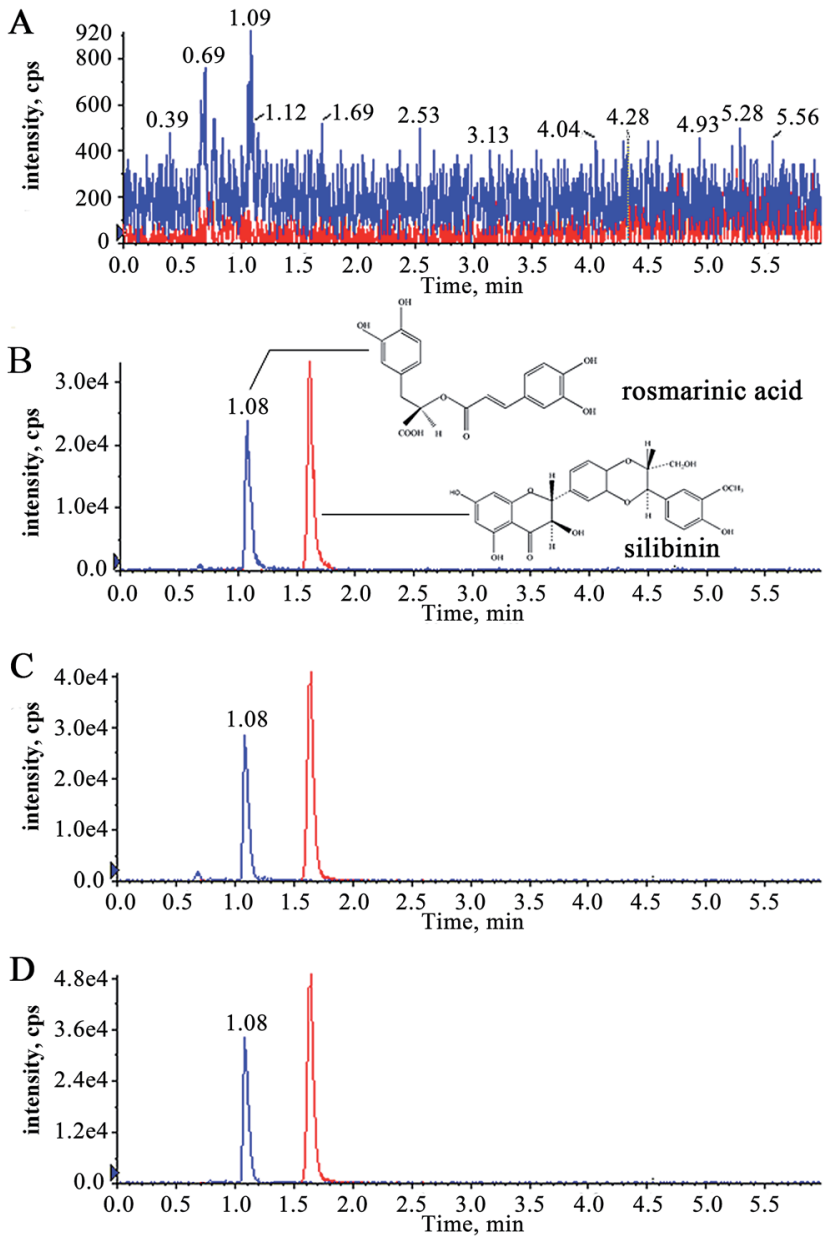

Fig. 1 Typical chromatograms of a blank rat plasma sample (A), a blank rat plasma sample spiked with RA (448.8 $\mathrm{ng} \mathrm{mL}^{-1}$ ) and I.S. (B), a rat plasma sample 10 min after intravenous administration of RA (C), a rat plasma sample $10 \mathrm{~min}$ after receiving oral doses of $50 \mathrm{mg} \mathrm{kg}^{-1}$ (D) and the chemical structures of RA and I.S.

paracellular diffusion with low intestinal absorption efficiency. ${ }^{24,25}$ Intestinal flora and intestinal epithelial cells usually transform polyphenols into low molecular weight metabolites, which decrease the intestinal absorption of polyphenols, such as catechins found in tea. ${ }^{26}$ In order to achieve rational clinical application and optimal dosage form design of drug, the study of absolute bioavailability is indispensable. Furthermore, dose proportionality of a drug is important for its safety and efficiency, because it could indicate whether dose-response relation is linear or not, which may affect effectiveness and toxicity. To the best of our knowledge, there is no report concerning bioavailability or dose proportionality of RA in vivo.

In the present paper, a validated LC-MS/MS method was developed for the determination of RA in rat plasma. Pharmacokinetic parameters were obtained following oral and intravenous dosing using DAS 3.0 software. Absolute bioavailability in rats was determined by comparing pharmacokinetic data after administration of single oral $\left(12.5,25\right.$ and $\left.50 \mathrm{mg} \mathrm{kg}^{-1}\right)$ and intravenous $\left(0.625 \mathrm{mg} \mathrm{kg}^{-1}\right)$ doses of RA. The dose proportionality of AUC and $C_{\max }$ were analyzed by power model.

\section{Materials and methods}

\section{Materials}

Rosmarinic acid (raw material) was purchased from Nanjing Zelang Medical Technology Co., Ltd. (Nanjing, China) and had a purity of mass fraction of more than $98.0 \%$. Rosmarinic acid and silibinin (purity $>99 \%$ ), used as a reference standard and an internal standard (I.S.), were obtained from the National Institute for the Control of Pharmaceutical and Biological Products (Beijing, China). Acetonitrile and formic acid (HPLC grade) were purchased from Merck and Tedia Company Inc. (Merk, Darmstadt, Germany). Purified water was prepared using a Milli-Q purification system (Millipore, Billerica, MA, USA). Other chemical reagents of analytical grade or better were obtained from Sinopharm Chemical Reagent Co. (Nanjing, China).

\section{Animal treatment}

Twenty-four Sprague Dawley male rats weighing 220-250 g were supplied by the Animal Center of Nanjing Medical University. Animals were housed in environmentally controlled conditions at $25 \pm 2{ }^{\circ} \mathrm{C}$ and $50 \pm 10 \%$ relative humidity under a $12 \mathrm{~h}$ darklight cycle. The rats were kept with free access to food and water until $12 \mathrm{~h}$ prior to the experiments. All procedures and experiments of this study were approved by the Animal Care and Use Committee of Nanjing University of Chinese Medicine, and its approved protocol is "Scientific Protocol (2007) Number 16 of Nanjing University of Chinese Medicine".

\section{LC-MS/MS conditions}

The LC-MS/MS system consisted of a Shimadzu LC-20A series liquid chromatograph (Shimadzu) and a QTRAP 5500 mass spectrometer (Applied Bio-systems, AB Sciex) equipped with an electro-spray ionization (ESI) source. The data acquisition and processing were performed using Analyst 1.5.2 software. The separation was performed on a Waters Acquity UHPLC BEH $\mathrm{C}_{18}$ column $(100 \times 2.1 \mathrm{~mm}$, i.d., $1.7 \mu \mathrm{m}$, Waters $)$ protected by a Van Guard BEH C $\mathrm{C}_{18}$ column $(5 \times 2.1 \mathrm{~mm}, 1.7 \mu \mathrm{m}$, Waters $)$ maintained at $40{ }^{\circ} \mathrm{C}$. The mobile phase consisting of a $0.5 \%$ formic acid aqueous solution and $0.1 \%$ formic acid acetonitrile solution $(60: 40, \mathrm{v} / \mathrm{v})$ was run at a flow rate of $0.3 \mathrm{~mL} \mathrm{~min}^{-1}$. The injection volume was $3 \mu \mathrm{L}$. The total run time for a LC-MS/MS analysis was $6 \mathrm{~min}$.

An ESI interface in the negative mode was used. The ion spray voltage was set at $-4.5 \mathrm{kV}$ and the turbo spray temperature was maintained at $500{ }^{\circ} \mathrm{C}$. Nebulizer gas (gas 1 ) and heater gas (gas 2) were set at 160 and $260 \mathrm{psi}$, respectively. The curtain gas was kept at $40 \mathrm{psi}$ and the interface heater was on. Nitrogen gas was used in all cases. Quantification was performed using MRM mode.

\section{Preparation of calibration and quality control (QC) samples}

Stock solutions of RA and silibinin (I.S.) were prepared in methanol at a concentration of 0.1122 and $0.1126 \mathrm{mg} \mathrm{mL}^{-1}$, respectively. Stock solutions were then diluted with methanol to 
produce a series of standard or QC working solutions at desired concentrations. The calibration standards were prepared by adding $10 \mu \mathrm{L}$ of the series of standard working solutions into $100 \mu \mathrm{L}$ of blank plasma to provide final concentrations at 8.976, 17.95, 44.88, 89.76, 224.4, 448.8, 1122, 2244, 5610, and 11220 ng $\mathrm{mL}^{-1}$. Low, medium and high levels of QC samples were prepared at $17.95,448.8$ and $5610 \mathrm{ng} \mathrm{mL}^{-1}$, respectively. The I.S. working solution of $2.252 \mu \mathrm{g} \mathrm{mL}^{-1}$ was also prepared by dilution of the stock solution with methanol. All the solutions were kept at $4{ }^{\circ} \mathrm{C}$ and brought to room temperature before use.

\section{Sample preparation}

A simple liquid-liquid extraction method was applied to extract RA and I.S. from the rat plasma. In an aliquot of $100 \mu \mathrm{L}$ of rat plasma, $10 \mu \mathrm{L}$ of the I.S. and $10 \mu \mathrm{L}$ of methanol (volume of the corresponding working solution for calibration curve and QC samples) and $16 \mu \mathrm{L}$ of formic acid/water $(1: 3, \mathrm{v} / \mathrm{v})$ were added. Then the mixture was vortexed for $1 \mathrm{~min}$ and $0.2 \mathrm{~mL}$ of acetone/ water $(70: 30, \mathrm{v} / \mathrm{v})$ solution was added, followed by adding $1 \mathrm{~mL}$ of ethyl acetate to each tube. Extraction was performed by vortex mixing the tubes for $2 \mathrm{~min}$, followed by centrifugation at $16000 \mathrm{rpm}$ for $3 \mathrm{~min}$. The organic layer was transferred to Eppendorf tubes and dried using a centrifugal concentrator. The residue was reconstituted in $100 \mu \mathrm{L}$ of water containing $25 \%$ acetone. After centrifugation at $16000 \mathrm{rpm}$ for $3 \mathrm{~min}$, aliquots of $3 \mu \mathrm{L}$ were injected into the UPLC-MS/MS system for analysis.

\section{Method validation}

The method was validated for selectivity, linearity, precision, accuracy, extraction recovery and stability according to the FDA guidelines for the validation of bio-analytical methods. ${ }^{27}$

Specificity. To investigate whether or not endogenous constituents interfered with the assay, the specificity of the method was tested by comparing the chromatograms of a blank rat plasma sample, a blank rat plasma sample spiked with RA (448.8 $\mathrm{ng} \mathrm{mL} \mathrm{mL}^{-1}$ ) and I.S. (2.252 $\mu \mathrm{g} \mathrm{mL}^{-1}$ ), a rat plasma sample 10 min after intravenous administration of RA, and a rat plasma sample $10 \mathrm{~min}$ after receiving oral doses of $50 \mathrm{mg} \mathrm{kg}{ }^{-1}$.

Linearity and lower limit of quantification (LLOQ). Calibration curves were prepared by assaying standard plasma samples at ten concentration levels. Calibration curves were prepared by plotting the peak area ratios between the analytes and the I.S. against the concentration of analytes.

The lower limit of quantification is defined as the lowest concentration on the calibration curve with an acceptable precision (RSD) not exceed $20 \%$ and RE (relative error) of accuracy should not deviate by more than $20 \%$.

Precision and accuracy. The intra-day precision and accuracy were evaluated by repeated analyses of QC samples at three different concentration levels $\left(17.95,448.8\right.$ and $5610 \mathrm{ng} \mathrm{mL} \mathrm{m}^{-1}$ ) from six replicates on the same day, while the inter-day precision and accuracy were evaluated on three independent days. The concentration of each sample was determined using the calibration curve prepared and analyzed on the same batch. Precision was evaluated by intra-day and inter-day RSD, which should not exceed 15\% except for the LLOQ. Accuracy was evaluated by comparing the observed concentration with the actual concentration and RE of accuracy should not deviate by more than $15 \%$ except for the LLOQ.

Matrix effect and recovery. The matrix effects were measured by comparing the peak areas of the analytes dissolved in the pretreated blank plasma with that of analytes working solutions containing equivalent amounts of the analytes. Recovery was determined by comparing the peak areas of extracted RA from the QC samples to those for RA prepared in methanol. This procedure was repeated six times at three QC concentration

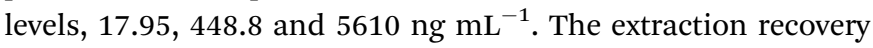
and matrix effect of the I.S. were also evaluated using the same procedure.

Stability. The stability of the analytes in rat plasma was assessed by analyzing QC samples at three concentration levels under three different sets of conditions. The short-term stability was determined with untreated QC samples stored for 24 hours at room temperature. The long-term stability was assessed after the untreated QC samples had been stored at $-20{ }^{\circ} \mathrm{C}$ for 15 days. The freeze-thaw stability was determined after three freeze-thaw cycles $\left(-20{ }^{\circ} \mathrm{C}\right.$ to room temperature as one cycle).

\section{Bioavailability and pharmacokinetics of RA in rats}

The validated method was applied to analyze the plasma concentrations of RA in rats after oral and intravenous administration of RA. Twenty-four male rats were randomly divided into four groups with six in each. Three groups were given RA at a single oral dose of $12.5,25$ and $50 \mathrm{mg} \mathrm{kg}^{-1}$, and one group received a single dose of RA of $0.625 \mathrm{mg} \mathrm{kg}^{-1}$ by intravenous injection via caudal vein after an overnight fasting period. The rats were fasted for the first $2 \mathrm{~h}$ with free access to water after dosing. Serial blood samples (approximately $0.2 \mathrm{~mL}$ ) were collected from the eyeground vein into $1.5 \mathrm{~mL}$ heparinized tubes at $0,2,5,10,20,30,45,60,90,120,180,240,360,480$ and $720 \mathrm{~min}$ after oral administration and at 0, 2, 5, 10, 20, 30, 45, $60,75,90,120,180,240$ and $360 \mathrm{~min}$ after intravenous injection. Plasma was isolated from the blood samples by cooling them for $2 \mathrm{~h}$ at $4{ }^{\circ} \mathrm{C}$, followed by centrifugation at $3000 \mathrm{rpm}$ for $10 \mathrm{~min}$. The collected plasma was transferred into $1.5 \mathrm{~mL}$ Eppendorf tubes and then stored at $-20{ }^{\circ} \mathrm{C}$ for analysis.

Pharmacokinetic parameters were estimated using Drug and Statistics 3.0 (DAS 3.0, Mathematical Pharmacology Professional Committee of China) employing the noncompartmental model. The oral bioavailability $(F)$ of RA is calculated by comparing the respective AUC after oral and intravenous administration according to the following equation:

$$
F \%=\frac{\text { oral } \mathrm{AUC}_{0-\infty}}{\text { iv } \mathrm{AUC}_{0-\infty}} \times \frac{\text { iv Dose }}{\text { oral Dose }} \times 100 \%
$$

\section{Statistical analyses}

Descriptive statistics were used to summarize the pharmacokinetic parameters for RA. Statistical comparisons of $\mathrm{AUC}_{0-t}$, $\mathrm{AUC}_{0-\infty}, C_{\text {max }}$ between the three doses were performed using an analysis of variance (ANOVA). Multivariable regression analysis was used to test associations between $\mathrm{AUC}_{0-t}, \mathrm{AUC}_{0-\infty}, C_{\max }$ and 
the dose. Dose proportionality for $\mathrm{AUC}_{0-t}, \mathrm{AUC}_{0-\infty}$ and $C_{\max }$ was assessed by linear regression of In-transformed parameters on the natural ln-transformed dose $\left[\ln (\mathrm{PK})=\beta_{0}+\beta_{1} \times \ln (\right.$ dose $\left.)\right]$. Values of the proportionality constant, $\beta_{1}$, and its corresponding $90 \%$ CI were estimated with the SPSS 19.0 software. The primary methodology used to assess dose proportionality from 12.5 to $50 \mathrm{mg} \mathrm{kg}^{-1}$ was a comparison of the $90 \%$ CI of the slopes with the modified acceptance range $\left[1+\left(\ln \left(\theta_{\mathrm{L}}\right) / \ln (r)\right), 1+\left(\ln \left(\theta_{\mathrm{H}}\right) /\right.\right.$ $\ln (r))]$ based on a power model, ${ }^{28,29}$ where $\theta_{\mathrm{L}}$ and $\theta_{\mathrm{H}}$ are the lower and upper limits of the confidence interval and $r$ is the maximal dose ratio for the study. Dose proportionality was assumed if the plot of pharmacokinetic parameter $v s$. dose indicated linearity and the $90 \%$ CI for the slope fell within the modified acceptance range.

\section{Results and discussions}

\section{LC-MS/MS development}

In the full scan mass spectra, the deprotonated molecular ions $[\mathrm{M}-\mathrm{H}]^{-}$of RA and silibinin (I.S.) $(\mathrm{m} / \mathrm{z}$ at 359.0 and 480.6$)$ were stable and exhibited higher abundance. Quantitation was performed using multiple reaction monitoring (MRM) of the transitions of $m / z 359.0 \rightarrow 160.9$ for RA and $480.6 \rightarrow 301.0$ for I.S., respectively. Declustering potential, collision energy and cell exit potential of RA and I.S. were optimized as $-70,-22$, $-15 \mathrm{~V}$ and $-210,-26,-21 \mathrm{~V}$, respectively. The optimized mass spectrometric parameters had a higher signal for both precursor ions and product ions mentioned above.

Selection of the LC conditions was key in order to obtain chromatograms with better peak responses. We found that acetonitrile-water can achieve higher peak responses and shorter analysis times for the target compounds in chromatograms. It was found that the peak shapes and responses of analytes were improved with an eluent consisting of water containing $0.5 \%$ formic acid and acetonitrile containing $0.1 \%$ formic acid (60:40, $\mathrm{v} / \mathrm{v}$ ). Satisfactory separation was achieved in $6 \mathrm{~min}$ by isocratic elution using the LC conditions described above.

\section{Method validation}

Specificity. Under the above LC-MS/MS conditions, the retention times of RA and I.S. were 1.08 and $1.61 \mathrm{~min}$, respectively. The typical chromatograms of a blank rat plasma sample, a blank rat plasma sample spiked with RA (448.8 $\left.\mathrm{ng} \mathrm{mL}^{-1}\right)$ and I.S., a rat plasma sample $10 \mathrm{~min}$ after intravenous administration of RA, a rat plasma sample $10 \mathrm{~min}$ after receiving oral doses of $50 \mathrm{mg} \mathrm{kg}^{-1}$, and the chemical structures of RA and I.S. are shown in Fig. 1. No obvious interferences were observed in these typical chromatograms of a blank plasma sample at the retention times of the analyte and the I.S.

Linearity and lower limit of quantification (LLOQ). Linearity for RA was obtained over the concentration range of 8.976$11220 \mathrm{ng} \mathrm{mL}^{-1}$. A typical standard curve was $y=0.0089 x-$ $0.3320\left(r^{2}=0.9980\right)$, where $y$ represents the peak area ratios of RA to the I.S. and $x$ represents the plasma concentrations of RA.

The linearity and lower limit of quantification (LLOQ) of RA in rat plasma was $8.976 \mathrm{ng} \mathrm{mL}^{-1}$ with an intra- and inter-day relative standard deviation (RSD) of less than $3.85 \%$, and an intra- and inter-day relative error (RE) of $-8.74 \%$ and $-7.88 \%$, which was sufficient for the pharmacokinetic studies of RA in rats.

Precision and accuracy. The intra- and inter-day precisions of this method for RA ranged from 5.70 to $6.32 \%$ and from 2.39 to $6.54 \%$ for each quality control (QC) level, respectively. The intraand inter-day accuracies for RA were $-9.18 \%$ to $5.57 \%$ and $-12.57 \%$ to $7.04 \%$, respectively. The results indicated that the present method was reliable and reproducible for the quantitative determination of RA.

Extraction recovery. The extraction recoveries of RA were $78.19 \pm 8.42,80.18 \pm 11.84$ and $72.03 \pm 6.18 \%$ at concentrations of $17.95,448.8$ and $5610 \mathrm{ng} \mathrm{mL}^{-1}$, respectively. The recovery of I.S. was $84.58 \pm 6.79 \%$. The results of the matrix effect of RA were in the range of $87.30-95.47 \%$. These are shown in Table 1.

Stability. Short-term stability showed good stability as responses varied no more than $\pm 8 \%$ at three QC concentrations. The long-term stability showed no obvious substance loss $(\mathrm{RE}<7 \%, \mathrm{RSD}<8 \%)$. The concentration variation after three freeze-thaw cycles was within $\pm 14 \%$ of nominal concentrations, which indicated that the analytes in rat plasma were all stable for 24 hours at room temperature, 15 days at $-20{ }^{\circ} \mathrm{C}$ and three cycles of freeze-thaw.

\section{Pharmacokinetic parameters and bioavailability study}

The validated analytical method was successfully applied to a pharmacokinetic study of RA in rats. The mean plasma concentration-time curves of RA after oral administration of $12.5,25,50 \mathrm{mg} \mathrm{kg}^{-1}$ and intravenous administration of $0.625 \mathrm{mg}$ $\mathrm{kg}^{-1}$ to rats are presented in Fig. 2. The corresponding pharmacokinetic parameters calculated using non-compartmental analysis are listed as mean \pm SD in Table 2.

As seen from Table 2 and Fig. 2, it was found that after single oral administration $\left(12.5,25\right.$ and $50 \mathrm{mg} \mathrm{kg}^{-1}$ ), RA could be absorbed rapidly into blood, and reached its peak concentration in plasma within $19 \mathrm{~min}$. After that RA eliminated slowly with $t_{1 /}$

Table 1 The matrix effects and extraction recoveries of RA and I.S. in rat plasma $(n=6)$

\begin{tabular}{|c|c|c|c|c|c|}
\hline Analytes & Concentration $\left(\mathrm{ng} \mathrm{mL} \mathrm{m}^{-1}\right.$ ) & Mean \pm SD $(\%)$ & RSD (\%) & Mean \pm SD (\%) & $\operatorname{RSD}(\%)$ \\
\hline \multirow{2}{*}{ RA } & 448.8 & $87.30 \pm 5.29$ & 6.06 & $80.18 \pm 11.84$ & 14.77 \\
\hline & 5610 & $94.71 \pm 4.88$ & 5.15 & $72.03 \pm 6.18$ & 8.59 \\
\hline Silibinin (I.S.) & 225.2 & $96.83 \pm 4.43$ & 4.58 & $84.58 \pm 6.79$ & 8.03 \\
\hline
\end{tabular}



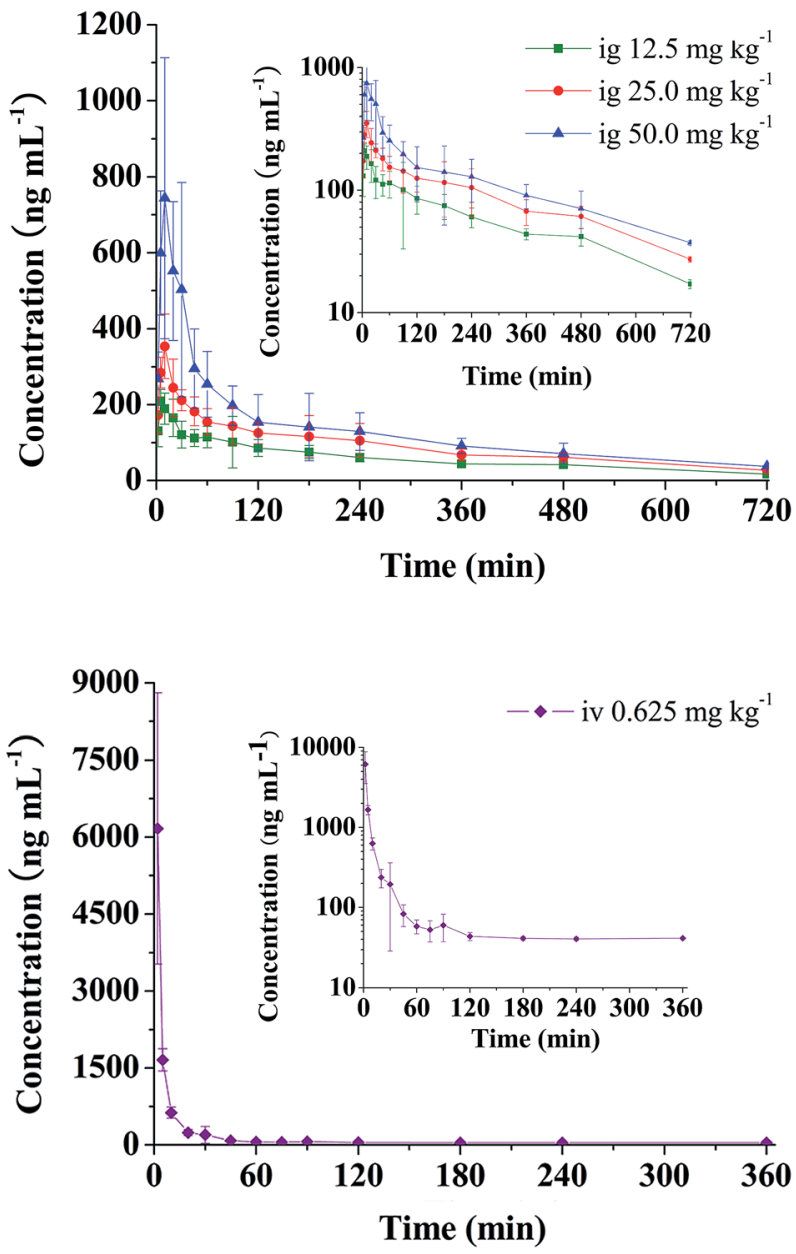

Fig. 2 Mean plasma concentration-time curves of RA in rats after administration of single oral $\left(12.5,25\right.$ and $\left.50 \mathrm{mg} \mathrm{kg}^{-1}\right)$ and intravenous $\left(0.625 \mathrm{mg} \mathrm{kg}^{-1}\right)$ doses.

${ }_{2}$ of 295.32-332.34 min and CL between 0.248 and $0.460 \mathrm{~L} \mathrm{~min}^{-1}$ $\mathrm{kg}^{-1}$. $C_{\max }$ values were estimated to be 215.21, 361.57 and $790.96 \mathrm{ng} \mathrm{mL}^{-1}$, respectively. The AUC increased with increasing doses, and the $\mathrm{AUC}_{0-t}$ values were 41789.84 , 64220.00 and 96070.00 (ng $\operatorname{min~} \mathrm{mL}^{-1}$ ), receptively. In addition, no significant difference was observed in $t_{1 / 2}$ and MRT $(p>0.05)$ at three dosages. The absolute oral bioavailabilities of RA in rats were quite low with values being $1.69 \pm 0.36 \%, 1.28 \pm 0.14 \%$ and $0.91 \pm 0.17 \%$, receptively.

Oral bioavailability is a complicated parameter that involves a number of chemical and physical processes. Poor bioavailability of RA may result from several different causes such as its intestinal absorption and metabolism. Its high hydrophilicity makes RA exhibit poor permeation across intestinal epithelial cells. $^{30}$

Besides, in rats orally administered with RA, the polyphenol was absorbed, degraded, and/or conjugated as $m$-hydroxyphenylpropionic acid, $m$-coumaric acid, and sulphated forms of caffeic acid and ferulic acid, ${ }^{20}$ which were then absorbed by a specific intestinal monocarboxylic acid transporter-mediated active process, ${ }^{21}$ before being excreted gradually in the urine.

Considering the low absolute bioavailability of RA and its derivatives' efficacy, the effects of RA may be explained not solely by the established absorption of RA, but also by the absorption of its microbial phenolic acid metabolites. The assigned effect of RA and its metabolites is a need for further research..$^{31-34}$

\section{Dose proportionality}

According to One-Way ANOVA analysis, the results of homogeneity of variance test statistics indicated that the variances of $C_{\max }, \mathrm{AUC}_{0-t}$ and $\mathrm{AUC}_{0-\infty}$ were not homogenous. The $C_{\max }$, $\mathrm{AUC}_{0-t}$ and $\mathrm{AUC}_{0-\infty}$ need to be ln-transformed. The results are summarized in Table 3. After curve estimation analysis with different models, relationships between $\ln C_{\max }$ and dose, ln $\mathrm{AUC}_{0-t}$ and dose, $\ln \mathrm{AUC}_{0-\infty}$ and dose could be well fitted with power model, as showed in Table 4 . Plots of the fitted function for the power model with associated $90 \%$ confidence intervals are presented for $\mathrm{AUC}_{0-t}, \mathrm{AUC}_{0-\infty}$ and $C_{\text {max }}$ in Fig. 3. Results of the assessment based on the power model are presented in Table 5 . The slopes (90\% confidence intervals (CIs)) were $0.586(0.466,0.707)$ for $\mathrm{AUC}_{0-t}, 0.553(0.433,0.673)$ for $\mathrm{AUC}_{0-\infty}$ and $0.887(0.679,1.095)$ for $C_{\max }$. The corresponding

Table 3 Test of homogeneity of variances

Parameters $C_{\max } \quad \ln C_{\max } \quad \mathrm{AUC}_{0-t} \quad \ln \mathrm{AUC}_{0-t} \quad \mathrm{AUC}_{0-\infty} \quad \ln \mathrm{AUC}_{0-\infty}$ $\begin{array}{lllllll}\text { Sig. } & 0.006 & 0.123 & 0.010 & 0.215 & 0.038 & 0.415\end{array}$

Table 2 Pharmacokinetic parameters of RA after single oral and intravenous administrations $(n=6)$

\begin{tabular}{|c|c|c|c|c|}
\hline Parameters & Oral (12.5 $\left.\mathrm{mg} \mathrm{kg}^{-1}\right)$ & Oral $\left(25 \mathrm{mg} \mathrm{kg}^{-1}\right)$ & Oral (50 mg kg $\left.{ }^{-1}\right)$ & Intravenous (0.625 $\left.\mathrm{mg} \mathrm{kg}^{-1}\right)$ \\
\hline $\mathrm{AUC}_{0-t}\left(\min \mathrm{ng} \mathrm{mL}^{-1}\right)$ & $41789.84 \pm 4673.43$ & $64220.00 \pm 9287.91$ & $96070.00 \pm 22151.45$ & $62412.99 \pm 14262.99$ \\
\hline $\mathrm{AUC}_{0-\infty}\left(\min \mathrm{ng} \mathrm{mL}^{-1}\right)$ & $51990.55 \pm 10945.85$ & $78517.08 \pm 8497.73$ & $111994.79 \pm 21458.01$ & $153368.64 \pm 83621.74$ \\
\hline$C_{\max }\left(\mathrm{ng} \mathrm{mL}^{-1}\right)$ & $215.21 \pm 29.32$ & $361.57 \pm 81.01$ & $790.96 \pm 358.41$ & $6166.89 \pm 2641.58$ \\
\hline$T_{\max }(\min )$ & $8.33 \pm 6.06$ & $10.83 \pm 4.92$ & $18.33 \pm 9.83$ & - \\
\hline$t_{1 / 2}(\min )$ & $332.34 \pm 168.77$ & $314.13 \pm 185.84$ & $295.32 \pm 72.29$ & $42.90 \pm 10.41$ \\
\hline $\mathrm{MRT}_{0-t}(\min )$ & $244.41 \pm 16.69$ & $243.20 \pm 18.91$ & $228.85 \pm 21.05$ & $50.12 \pm 14.94$ \\
\hline $\mathrm{MRT}_{0-\infty}(\mathrm{min})$ & $439.13 \pm 190.70$ & $434.88 \pm 211.45$ & $366.64 \pm 56.78$ & $1747.51 \pm 1436.59$ \\
\hline $\mathrm{CL}\left(\mathrm{L} \min ^{-1} \mathrm{~kg}^{-1}\right)$ & $0.25 \pm 0.05$ & $0.32 \pm 0.03$ & $0.46 \pm 0.08$ & $0.01 \pm 0.00$ \\
\hline$V\left(\mathrm{~L} \mathrm{~kg}^{-1}\right)$ & $111.83 \pm 31.14$ & $141.81 \pm 69.63$ & $197.65 \pm 63.60$ & $9.41 \pm 2.86$ \\
\hline$F(\%)$ & $1.69 \pm 0.36$ & $1.28 \pm 0.14$ & $0.91 \pm 0.17$ & - \\
\hline
\end{tabular}


Table 4 Model summary of different equations

\begin{tabular}{llll}
\hline & \multicolumn{2}{l}{$R$ square } & \\
\cline { 2 - 3 } Equation & $\ln C_{\max }$ & $\ln \mathrm{AUC}_{0-t}$ & $\ln \mathrm{AUC}_{0-\infty}$ \\
\hline Linear & 0.766 & 0.771 & 0.749 \\
Logarithmic & 0.756 & 0.804 & 0.792 \\
Inverse & 0.694 & 0.780 & 0.778 \\
Quadratic & 0.769 & 0.805 & 0.794 \\
Cubic & 0.769 & 0.805 & 0.794 \\
Compound & 0.779 & 0.771 & 0.745 \\
Power & 0.778 & 0.808 & 0.791 \\
Growth & 0.779 & 0.771 & 0.745 \\
Exponential & 0.779 & 0.771 & 0.745 \\
Logistic & 0.779 & 0.771 & 0.745
\end{tabular}
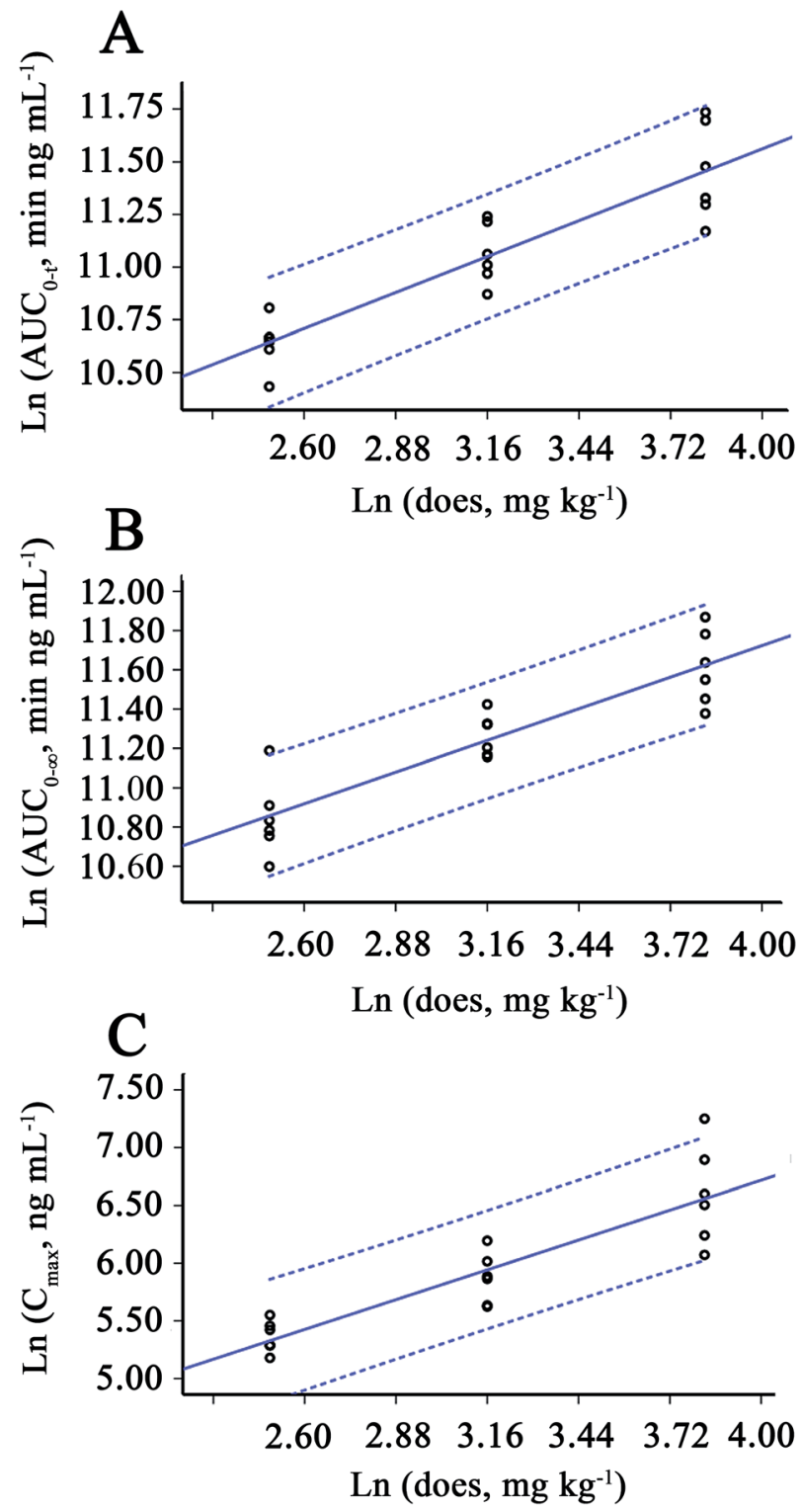

Fig. 3 Relationship between the extent of systemic exposure and dose following oral administration of RA ranged from 12.5 to $50 \mathrm{mg}$ $\mathrm{kg}^{-1}$ in rats. The empty circles are the individual observed values; the solid lines are the fitted values based on the power model, and the dashed lines are the $90 \% \mathrm{Cls}$. (A), $\mathrm{AUC}_{0-t} ;(\mathrm{B}), \mathrm{AUC}_{0-\infty} ;(\mathrm{C}), \mathrm{C}_{\max }$.
Table 5 Assessment of dose proportionality of RA based on power model

\begin{tabular}{llll}
\hline & & \multicolumn{2}{l}{$\mathrm{RA}$} \\
\cline { 3 - 4 } Parameters & Acceptance range & $\beta_{1}$ & $90 \%$ confidence interval \\
\hline $\mathrm{AUC}_{0-t}$ & $0.839-1.161$ & 0.586 & $0.466-0.707$ \\
$\mathrm{AUC}_{0-\infty}$ & $0.839-1.161$ & 0.553 & $0.433-0.673$ \\
$C_{\max }$ & $0.839-1.161$ & 0.887 & $0.679-1.095$
\end{tabular}

90\% CIs for $\mathrm{AUC}_{0-t}, \mathrm{AUC}_{0-\infty}$ and $C_{\max }$ spanned the acceptance interval $(0.839,1.161)$ defined by the equations for $r=50 / 12.5$, $\theta_{\mathrm{L}}=0.8$ and $\theta_{\mathrm{H}}=1.25$, indicating inconclusive results.

\section{Conclusions}

In summary, it has been firstly carried out to comprehensively investigate absolute bioavailability, pharmacokinetics, and dose proportionality on the pharmacokinetics of single oral dose of RA. The absolute bioavailability of RA in rats was estimated as $1.69 \%, 1.28 \%$ and $0.91 \%$ after oral administration of RA at the doses of 12.5, 25 and $50 \mathrm{mg} \mathrm{kg}^{-1}$. The relationships between pharmacokinetic parameters $\left(C_{\max }, \mathrm{AUC}_{0-t}\right.$ and $\left.\mathrm{AUC}_{0-\infty}\right)$ of $\mathrm{RA}$ and dose could be well fitted with power model. Pharmacokinetic properties of RA in rats after oral administration were characterized as rapid absorption, middle-speed elimination and poor absolute bioavailability. Analysis by power model demonstrated that systemic exposure exhibited lack of dose proportionality over the dose ranged from 12.5 to $50 \mathrm{mg} \mathrm{kg}^{-1}$. The data presented in this study could provide useful information for its rational clinical application and optimal dosage form design.

\section{Declaration of interest}

The authors declare no conflict of interest.

\section{Acknowledgements}

This study was financially supported by the Priority Academic Program Development (PAPD) fund of Jiangsu Higher Education Institution and The Natural Science Foundation of Jiangsu Province (No. BK20141465).

\section{References}

1 M. R. Al-Sereiti, K. M. Abu-Amer and P. Sen, Indian J. Exp. Biol., 1999, 37, 124-130.

2 M. Heinrich, J. Kufer, M. Leonti and M. Pardo-de-Santayana, J. Ethnopharmacol., 2006, 107, 157-160.

3 P. Ramirez, F. J. Senoran, E. Ibanez and G. Reglero, J. Chromatogr. A, 2004, 1057, 241-245.

4 Y. Peng, J. Yuan, F. Liu and J. Ye, J. Pharm. Biomed. Anal., 2005, 39, 431-437.

5 M. E. González-Trujano, E. I. Peña, A. L. Martínez, J. Moreno, P. Guevara-Fefer, M. Déciga-Campos and F. J. López-Muñoz, J. Ethnopharmacol., 2007, 111, 476-482. 
6 X. Chu, X. Ci, J. He, L. Jiang, M. Wei and Q. Cao, Molecules, 2012, 17, 3586-3598.

7 S. K. Ku, E. J. Yang, K. S. Song and J. S. Bae, Food Chem. Toxicol., 2013, 59, 311-315.

8 R. Domitrović, M. Skoda, M. V. Vasiljev, O. Cvijanović, P. E. Pernjak and M. B. Stefan, Food Chem. Toxicol., 2013, 51, 370-378.

9 D. O. Moon, M. O. Kim, J. D. Lee, Y. H. Choi and G. Y. Kim, Cancer Lett., 2010, 288, 183-191.

10 K. A. Scheckel, S. C. Degner and D. F. Romagnolo, J. Nutr., 2008, 138, 2098-2105.

11 M. J. Jordán, V. Lax, M. C. Rota, S. Lorán and J. A. Sotomayor, J. Agric. Food Chem., 2012, 60, 9603-9608.

12 G. S. Li, W. L Jiang, J. W. Tian, G. W. Qu, H. B. Zhu and F. H. Fu, Phytomedicine, 2010, 17, 282-888.

13 H. P. Dong, S. J. Park, J. M. Kim, W. Y. Jung and J. H. Ryu, Fitoterapia, 2010, 81, 644-648.

14 Y. Q. Liu, Q. Cai, C. Liu, F. W. Bao and Z. Q. Zhang, J. Anal. Methods Chem., 2014, 2014, 617367, 9 pages.

15 X. Li, Y. Chen, Y. Cai, G. Liu, J. Jia and Y. Wang, J. Chromatogr. B: Anal. Technol. Biomed. Life Sci., 2005, 820, 41-47.

16 X. Y. Wang, X. H. Ma, W. Li, Y. Chu, J. H. Guo, S. M. Li, J. M. Wang, H. C. Zhang, S. P. Zhou and Y. H. Zhu, J. Pharm. Biomed. Anal., 2013, 86, 82-91.

17 X. J. Lai, L. Zhang, J. S. Li, H. Q. Liu, X. H. Liu and L. Q. Di, Fitoterapia, 2011, 82, 883-888.

18 J. Y. Jia, Y. L. Lu, X. C. Li, G. Y. Liu, S. J. Li, Y. Liu, Y. M. Liu, C. Yu and Y. P. Wang, Curr. Ther. Res., 2010, 71, 260-271.

19 X. Li, C. Yu, Y. Lu, Y. Gu, J. Lu, W. Xu, L. Xua and Y. Wang, Drug Metab. Dispos., 2007, 35, 234-239.
20 S. Baba, N. Osakabe, M. Natsume and J. Terao, Life Sci., 2004, 75, 165-178.

21 Y. Konishi, Y. Hitomi, M. Yoshida and E. Yoshioka, J. Agric. Food Chem., 2005, 53, 4740-4746.

22 J. Sun, L. Zhang, J. Song, S. Tian, C. Huang, Z. Feng, Y. Lv and G. Du, J. Ethnopharmacol., 2013, 148, 617-623.

23 Y. T. Wu, Y. F. Chen, Y. J. Hsieh, I. Jaw, M. S. Shiao and T. H. Tsai, Int. J. Pharm., 2006, 326, 25-31.

24 Y. Konishi and S. Kobayashi, Biosci., Biotechnol., Biochem., 2005, 69, 583-591.

25 Y. Konishi, Y. Hitomi and E. Yoshioka, J. Agric. Food Chem., 2004, 52, 2527-2532.

26 L. Zhang, Y. Wang, D. Li, C. T. Ho, J. Li and X. Wan, Food Funct., 2016, 7, 1273-1281.

27 http://www.fda.gov/downloads/drugs/, accessed October 2013.

28 B. P. Smith, F. R. Vandenhende, K. A. Desante, N. A. Farid, P. A. Welch and J. T. Callaghan, Pharm. Res., 2000, 17, 1278-1283.

29 V. S. Sethuraman, S. Leonov, L. Squassante, T. R. Mitchell and M. D. Hale, Pharm Stat., 2007, 6, 35-41.

30 Z. Qiang, Z. Ye, C. Hauck, P. A. Murphy, J. A. McCoy, M. P. Widrlechner, M. B. Reddy and S. Hendrich, J. Ethnopharmacol., 2011, 137, 1107-1112.

31 T. Yasuda, A. Takasawa, T. Nakazawa, J. Ueda and K. Ohsawa, J. Pharm. Pharmacol., 2003, 55, 239-244.

32 I. M. Chung, J. J. Lim, M. S. Ahn, H. N. Jeong, T. J. An and S. H. Kim, J. Ginseng Res., 2016, 40, 68-75.

33 S. F. Nabavi, K. P. Devi, D. S. Malar, A. Sureda, M. Daglia and S. M. Nabavi, Mini-Rev. Med. Chem., 2015, 15, 776-788.

34 T. Silva, C. Oliveira and F. Borges, Expert Opin. Ther. Pat., 2014, 24, 1257-1270. 